\title{
CHANGE MANAGEMENT: THE PEOPLE DIMENSION OF CHANGE
}

Change management is the process, tools and techniques to effectively manage people and the associated human resource issues that surface when implementing business changes. Change management as a field of study finds its roots in two areas: business process improvement and psychology. The ADKAR model for change management as the diagnostic tool helps employees understand where they are in the change process. A manager can use this tool to identify gaps in his change management process and to provide effective coaching for his employees.

\section{Introduction}

Change management is the process, tools and techniques to effectively manage people and the associated human resource issues that surface when implementing business changes. Some authors integrate change management techniques with business improvement methodologies. This integrated approach is neither right or wrong. What is important is that you can recognize the difference between the two and understand the relationships between business improvement techniques and change management.

Change management as a field of study finds its roots in two areas: business process improvement and psychology. From the business process improvement disciplines such as total quality management (TQM) and business process reengineering (BPR), change management came about after many project failures. The root cause of many failures was a lack of change leadership and poor management of employee resistance to change.

In fact many process improvement disciplines that were "engineering" centric and problem solving in nature ignored change management.

From the psychology field, change management was recognized early on as a necessary component to manage the "human side" of change in the workplace. However, the soft and personal approach to managing change, sometimes referred to as the "touchy feely" approach, did not fit well with the problem-solving staff members so often picked to tackle critical business issues.

As a result, the marriage of business process improvement (meant in this case to comprehensively cover any business change including new business models, business processes, technology or restructuring) and change management took many years to develop. Early change management books were authored beginning in the early 80's. However, integrated models for designing business solu- tions and managing the change process did not appear until the late 90's and many of these models are still not widely recognized.

Research has shown clearly that projects that effectively integrate change management as a part of their business change are more successful and received better by those impacted by the change.

Change management occurs on two levels: the organizational level and the individual level. This framework of viewing change management from the management view and the employee view is critical for understanding.

The field of change management can be confusing and sometimes complicated to research and study, especially for new practitioners. Change management is the application of many different ideas from the engineering, business and psychology fields. As changes in organizations have become more frequent and a necessity for survival, the body of knowledge known as "change management" has also grown to encompass more skills and knowledge from each of these fields of study.

While this may be a good trend overall, the result for many change leaders is growing confusion about what change management really means.

Change Management: The convergence of two fields of thought

To understand change management as we know it today, you need to consider two converging and predominant fields of thought: an engineer's approach to improving business performance and a psychologist's approach to managing the human-side of change.

The table below summarises the key differences and contrasts the two approaches in terms of focus, business practice, measures of success and perspective on change.

\footnotetext{
* Ing. Mariana Strenitzerová, PhD.

Department of Communications, Faculty of Operation and Economics of Transport and Communications, University of Žilina, Moyzesova 20, 01026 Žilina, Slovak Republic, Tel.: +421-41-5133131, Fax: +421-41-5655 615, E-mail: Mariana.Strenitzerova@fpedas.utc.sk
} 


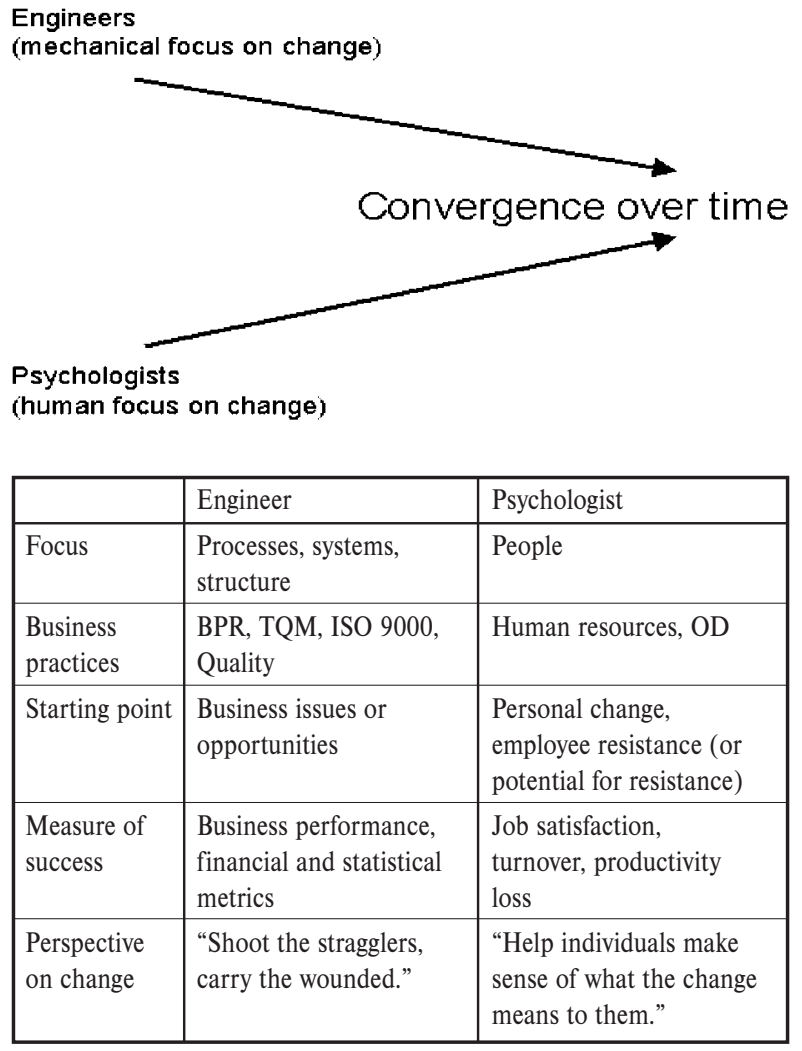

Today, the term "change management" takes on a variety of meanings. The most practical and useful definition is:

Change management is the process, tools and techniques to manage the people-side of business change to achieve the required business outcome, and to realize that business change effectively within the social infrastructure of the workplace.

This definition allows practitioners to separate change management as a practice area from business improvement techniques. So whether you are doing Six Sigma, BPR, TQM or some other technique to improve business performance, change management can be viewed as an essential competency to overlay and integrate with these methods.

\section{Change Management: Definitions and Strategies}

In thinking about what is meant by "change management," at least three basic definitions come to mind:

1. The task of managing change

2. An area of professional practice

3. A body of knowledge

\section{The Task of Managing Change}

The first and most obvious definition of "change management" is that the term refers to the task of managing change. The obvious is not necessarily unambiguous. Managing change is itself a term that has at least two meanings.
One meaning of managing change refers to the making of changes in a planned and managed or systematic fashion. The aim is to more effectively implement new methods and systems in an ongoing organization. The changes to be managed lie within and are controlled by the organization. However, these internal changes might have been triggered by events originating outside the organization, in what is usually termed "the environment." Hence, the second meaning of managing change, namely, the response to changes over which the organization exercises little or no control (e.g., legislation, social and political upheaval, the actions of competitors, shifting economic tides and currents, and so on). Researchers and practitioners alike typically distinguish between a knee-jerk or reactive response and an anticipative or proactive response.

\section{An Area of Professional Practice}

The second definition of change management is "an area of professional practice."

There are dozens, if not hundreds, of independent consultants who will quickly and proudly acknowledge that they are engaged in planned change, that they are change agents, that they manage change for their clients, and that their practices are change management practices. There are numerous small consulting firms whose principals would acknowledge these same statements about their firms. And most of the major management consulting firms claim to have a change management practice area.

Some of these change management experts claim to help clients manage the changes they face, the changes happening to them. Others claim to help clients make changes. Still others offer to help by taking on the task of managing changes that must be made. In almost all cases, the process of change is treated separately from the specifics of the situation. It is the task of managing this general process of change that is laid claim to by professional change agents.

\section{A Body of Knowledge}

Stemming from the view of change management as an area of professional practice there arises yet a third definition of change management: the content or subject matter of change management. This consists chiefly of the models, methods and techniques, tools, skills, and other forms of knowledge that go into making up any practice.

The content or subject matter of change management is drawn from psychology, sociology, business administration, economics, industrial engineering, systems engineering, and the study of human and organizational behaviour. For many practitioners, these component bodies of knowledge are linked and integrated by a set of concepts and principles known as General Systems Theory (GST). It is not clear whether this area of professional practice should be termed a profession, a discipline, an art, a set of techniques, or a technology. For now, suffice it to say that there is a large, reasonably cohesive albeit somewhat eclectic body of knowledge underlying the practice and on which most practitioners would agree even if their application of it does exhibit a high degree of variance.

To recapitulate, there are at least three basic definitions of change management: 
1. The task of managing change (from a reactive or a proactive posture)

2. An area of professional practice (with considerable variation among practitioners)

3. A body of knowledge (consisting of models, methods, techniques, and other tools)
To use the ADKAR model effectively, you will need to understand the underlying framework for change initiatives. In the diagram below, change happens on two dimensions: the business dimension (vertical axis) and the people dimension (horizontal axis). Successful change happens when both dimensions of change occur simultaneously.

The table below summarises four basic strategies of change management.

\begin{tabular}{|l|l|}
\hline Strategy & Description \\
\hline Rational-Empirical & $\begin{array}{l}\text { People are rational and will follow their self-interest - once it is revealed to them. Change is based on the } \\
\text { communication of information and the proffering of incentives. }\end{array}$ \\
\hline Normative-Reeducative & $\begin{array}{l}\text { People are social beings and will adhere to cultural norms and values. Change is based on redefining and reinterpreting } \\
\text { existing norms and values, and developing commitments to new ones. }\end{array}$ \\
\hline Power-Coercive & $\begin{array}{l}\text { People are basically compliant and will generally do what they are told or can be made to do. Change is based on the } \\
\text { exercise of authority and the imposition of sanctions. }\end{array}$ \\
\hline Environmental-Adaptive & $\begin{array}{l}\text { People oppose loss and disruption but they adapt readily to new circumstances. Change is based on building a new } \\
\text { organization and gradually transferring people from the old one to the new one. }\end{array}$ \\
\hline
\end{tabular}

\section{3. "ADKAR" - A Model for Change Management}

Prosci developed the ADKAR model in 2001 after research with more than 700 companies undergoing major change projects. This model is intended to be a coaching tool to help employees through the change process. The ADKAR model is not an organizational change management model or strategy.

The ADKAR model for change management as the diagnostic tool helps employees understand where they are in the change process. As a manager, you can use this tool to identify gaps in your change management process and to provide effective coaching for your employees. The ADKAR model can be used to:

- Diagnose employee resistance

- Help employees transition through the change process

- Create a successful action plan for personal and professional advancement during change

- Develop a change management plan for your employees

The ADKAR model has the ability to identify why changes are not working and help you take the necessary steps to make the change successful. You will be able to break down the change into parts, understand where the change is failing and address that impact point.

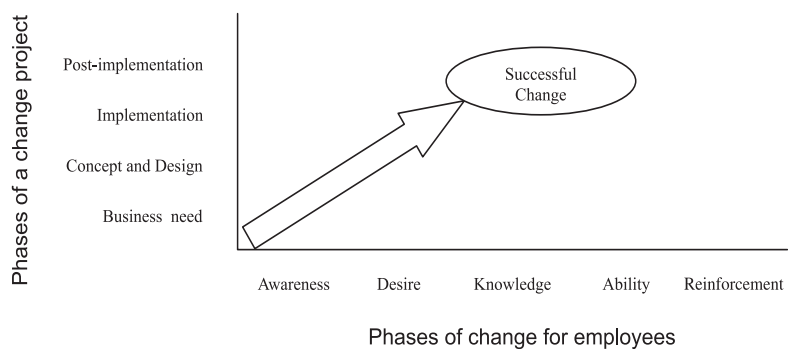

ffective management of the people dimension of change requires managing five key phases that form the basis of the ADKAR model:

- Awareness of the need to change

- Desire to participate and support the change

- Knowledge of how to change (and what the change looks like)

- Ability to implement the change on a day-to-day basis

- Reinforcement to keep the change in place 


\section{Conclusion}

This contribution presents an overview of the ADKAR model for change management. This diagnostic tool helps employees understand where they are in the change process. As a manager, you can use this tool to identify gaps in your change management process and to provide effective coaching for your employees.
The power of the ADKAR model is that it creates focus on the first element that is the root cause of failure. When you approach a change using this model, you can immediately identify where the process is breaking down and which elements are being overlooked. This avoids generic conversations about the change that rarely produce actionable steps.

\section{References}

[1] JURAJ CAJCHAN, OL'GA PONIŠČIAKOVÁ: Principles of process managing, V. International conferences in Transport, Vysoke Tatry, October 2002

[2] www.change-management.com

[3] www.prosci.com 